\title{
Comparison of the Electromyographic Activity in the Lower Trapezius Muscle According to Four Different Types of Exercises in Healthy Adults
}

\author{
Gyeong Ju Seo', Ji Won Park², Yonghyun Kwon ${ }^{3}$
}

'Rehabilitation Center, Daegu Hospital of Korea Workers' Compensation \& Welfare Service, Daegu; ${ }^{2}$ Department of Physical Therapy, College of Bio and Medical Science, Daegu Catholic University, Gyeongsan; ${ }^{3}$ Department of Physical Therapy, Yeungnam University College, Daegu, Korea

Purpose: This study examined the most effective exercise while performing shoulder abduction below ninety degrees.

Methods: Thirty two healthy individuals (17 males, 15 females) participated and performed four exercises, 1) Posterior fly, 2) Prone row, 3) Modified prone cobra, and 4) External rotation in the prone position. Surface electromyography (sEMG) was used to measure the electrical activities for the lower, middle and upper fiber of trapezius and serratus anterior.

Results: A significant difference in the muscle activities of the upper/middle/lower trapezius and serratus anterior was observed among the three different positions in terms of the PF (posterior fly), PR (prone row), and MPC (modified prone cobra) $(p<0.05)$. In post-hoc analysis, the activities of the lower and upper trapezius were significantly higher than those of the upper trapezius and serratus anterior $(p<0.05)$. In addition, in ERP (external rotation in prone), there was a significant difference in each activity of the muscles. Post-hoc results indicated that the upper trapezius showed greater EMG activity than the other three muscles.

Conclusion: External rotation in the prone position revealed the highest activation of the lower trapezius compared to upper trapezius muscle activity. This may be particularly useful in isolating the lower trapezius in cases where excessive scapular elevation is noted. Therefore, the most effective lower trapezius exercise should be performed below ninety degrees of shoulder abduction.

Keywords: Lower trapezius, Exercise position, Electromyography.

\section{서 론}

어깨 관절(shoulder complex)은 기본적으로 불안정한 구조를 지니고 있고 다양한 근육의 작용을 통하여 보완하는 대표적인 관절이다.,2 어깨 관절을 이루는 것 중에 하나인 어깨뼈(scapula)는 움직임과 함께 자세를 조절하는 중요한 구조물일 뿐만 아니라, 어깨의 움직임(mobility)과 안정성(stability)에 있어서도 중요한 역할을 한다. 어깨빼의 안 정된 움직임은 돌림근띠 파열(rotator cuff tear)이나 끼임 증후군(impingement syndrome)과 같은 어깨의 병리학적 문제를 예방하는데 중 요한 역할을 하며, ${ }^{3}$ 어깨뼈의 안정성과 움직임을 만들어 내는 것은 대 부분 등세모근(trapezius)과 앞톱니근(serratus anterior)의 활동에 의해 이루어진다. ${ }^{4.5}$

등세모근의 섬유 중 어느 하나라도 약화가 되면 길이 장력 관계 (length-tension relationship)와짝힘(force couple)에 변화가 발생하고 근
불균형이 나타나며 근 지구력이 저하되어 어깨위팔리듬(scapulo-humeral rhythm)에 부정적인 영향을 끼칠 수 있다. ${ }^{36}$ 그 중 아래등세모근 의 수행은 정상적인 어깨위팔리듬에 필수적인 요소이다. 등세모근의 근육 불균형은 위등세모근이 단축되고 아래등세모근이 약해질 때 발생 된다고 하였고, 위등세모근의 근력에 대한 아래등세모근의 근 력 비율을 향상시키는 운동은 이러한 근육 불균형을 감소시키고 정 상적인 어깨 자세를 향상시킨다고 보고하고 있다. 또한 아래등세모 근의 약화는 어깨뼈의 역학적인 기전을 저하시키고 불안정성과 어깨 의 병리적 상태를 악화 시킬 수 있다.710 아래등세모근의 근력 증진을 위해 다양한 운동이 제시되고 있으며, ${ }^{11-16}$ 특히 슈퍼맨 자세에서의 운 동 방법이 아래등세모근의 근력 증진에 많은 영향을 끼친다고 보고 되고 있다. ${ }^{17}$

현재 아래등세모근은 어깨뼈의 정상적인 관절 운동에 중요하다고 알려져 있고 아래등세모근의 활성화를 위해 슈퍼맨 자세와 같은 어
Received Apr 2, 2019 Revised Apr 17, 2019

Accepted Apr 25, 2019

Corresponding author Yonghyun Kwon

E-mail yhkwon@ync.ac.kr
Copylight (C2019 The Korean Society of Physical Therapy

This is an Open Access article distribute under the terms of the Creative Commons Attribution Non-commercial License (Http:// creativecommons.org/license/by-nc/4.O.) which permits unrestricted non-commercial use, distribution, and reproduction in any medium, provided the original work is properly cited. 
깨 관절 각도를 완전히 올려 시행하는 운동이 대부분이다. 하지만 어 깨 손상 환자의 초기 시 굽힘이나 벌림의 각도가 완전하지 않아, 이차 적인 위험을 야기 시킬 수 있다. ${ }^{18}$ 어깨 굽힘이나 벌림의 각도가 $90^{\circ}$ 이 하로 유지되어 운동을 수행해야 하는데 $90^{\circ}$ 이하로 유지하는 아래등 세모근의 운동은 다양하지 않고 연구가 미비한 실정이다. 따라서, 본 연구의 목적은 정상 성인을 대상으로 어깨 관절에 있어 $90^{\circ}$ 이하에서 수행 될 수 있는 운동 방법을 찾아 운동 형태에 따른 근 활성도를 알 아보고 아래등세모근의 근력 증진을 위해 가장 적합한 운동 자세를 찾아보고자하였다.

\section{연구 방법}

\section{1. 연구대상}

본 연구는 대구광역시에 소재한 $\mathrm{D}$ 병원에서 근무하고 있는 정상성인 중에서 연구의 목적을 충분히 이해하고 참여하겠다고 동의한 32 명을 대상으로 하였다. 선정기준은 최근 1 년 간 어깨의 근골격계 이상이 없 는 자, 선청적인 기형, 정형 외과적 질환이나 변형이 없는 자, 신경학적 으로 손상이 없는 자, 어깨 운동 동작을 수행할 때 통증을 호소하지 않는 자, 관절 구축과 관절가동범위의 제한이 없는 자를 선정 하였다.
대상자들로부터 일반적인 특성을 알아보기 위해 실험 전 나이, 신 장, 체중, 우세측 팔 등 전반적인 정보를 획득하고 우세측 팔이 왼팔 인 자는 대상자에서 배제하였다. 실험 전 대상자들에게 본 실험의 목 적과 내용, 방법에 대해 충분히 설명하고, 이해하고 자발적으로 참여 의사를 밝힌 자에 한해서 실험을 시행하였다. 또한, 본 연구는 임상시 험심사위원회(institutional review board, IRB)에 의뢰하여 승인 (승인 번호: CUIRB-2017-0027)을 받은 후 연구 진행을 하였다.

\section{2. 운동방법}

아래등세모근 근력 운동 시 실험의 일관성을 위해 높낮이 조절이 가 능한 테이블을 사용하였다. 엎드린 자세에서 정상적인 하지 정렬을 위해 정강이뼈 원위부에 베개를 받쳤으며, 목뼈 관절의 굽힘이나 폄 이 일어나지 않도록 하였다. 대상자들은 서로 다른 네 가지 운동 자세 에서 5 초간 자세를 유지하였고 정확한 동작을 수행할 수 있도록 관 절 각도계로 검사 자세를 설정하고 검사자가 구두 지시를 하였다. 각 동작은 3 번씩 반복하여 실시하였으며 운동 동작의 순서는 무작위로 실시하였고, 근 피로의 최소화를 위하여 반복 측정 전에는 30 초 간 휴식 시간을, 다른 동작 수행 전에는 10 분간 휴식 시간을 제공하였 다. 본 연구에서는 아래등세모근을 활성화 시킬 수 있는 운동 방법
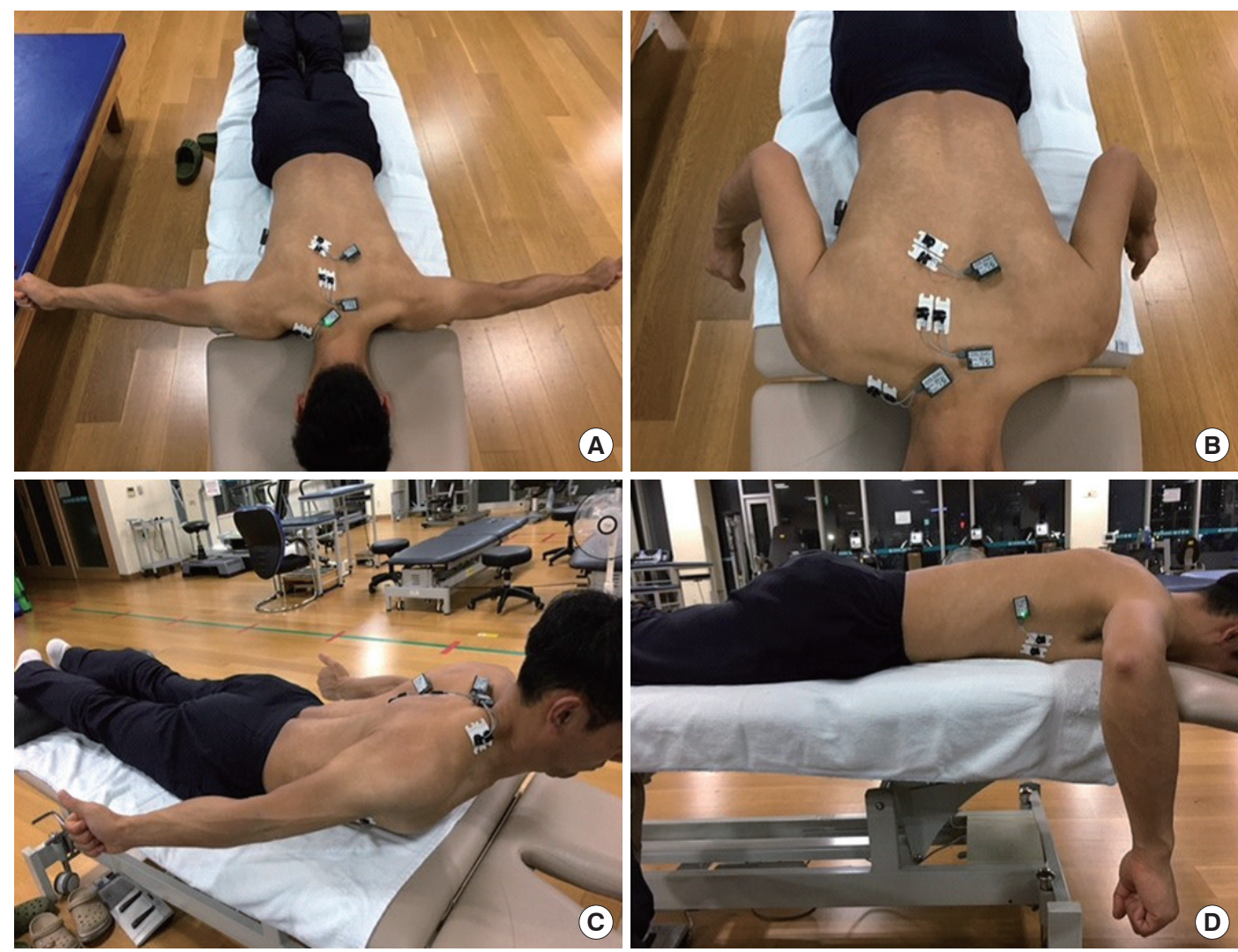

Figure 1. Four types of exercise for activation of trapezius and serratus anterior

A: posterior fly, B: prone row, C: modified prone cobra, D: external rotation in prone position 
네 가지를 이용하여 근 활성도를 측정하였다.

(1) posterior fly (PF) 운동

대상자는 높낮이 조절이 가능한 테이블에 바로 엎드린 자세(prone position)로 엄지손가락이 하늘로 향하게 어깨 관절을 바깥 돌림한 채 로 $90^{\circ}$ 벌림 위치를 수행하였다. 이때 팔꿈치 관절은 완전히 폄 상태가 유지되도록 하였다. 대상자는 어깨뼈를 내림 시키면서 양 팔을 하늘 로 향해 들어 올린 상태에서 등척성 운동을 할 수 있게 하였으며, 몸 통을 들어 올리는 보상작용이 일어나지 않도록 하였다.19

\section{(2) prone row (PR) 운동}

대상자는 높낮이 조절이 가능한 테이블에 바로 엎드린 자세에서 팔 꿈치 관절을 $90^{\circ}$ 로 굽히고 몸통과 팔사이의 간격은 $40^{\circ}$ 가 되게 하여 치료 테이블에 부딪히지 않도록 하였다. 대상자는 어깨 관절의 폄 동 작을 수행하면서 위로 바로 들어 올린 자세를 취하도록 하였다. 최대 힘을 측정하며 팔이 움직이지 않는 등척성 운동을 실시하였으며, 다 른 보상작용이 일어나지 않도록 하였다. ${ }^{20}$

\section{(3) modified prone cobra (MPC) 운동}

대상자는 높낮이 조절이 가능한 테이블에 바로 엎드린 자세에서 팔 꿈치 관절은 완전한 폄 동작을 수행하였다. 이때 엄지손가락이 하늘 을 향하게 하고 손바닥은 바깥쪽을 향하면서, 어깨 관절의 바깥 돌림 이 유발되도록 하였다. 손가락이 발쪽으로 향하게 팔을 아래로 내리 면서 위쪽으로 들어 올리면서 몸통을 펴도록 하여 가슴을 치료 테이 블에서 $10 \mathrm{~cm}$ 들어 올리도록 하였다. 대상자가 최대 힘으로 자세를 유 지하게 하고 팔의 움직임이 일어나지 않도록 하였다. ${ }^{18}$

\section{(4) external rotation in prone position (ERP) 운동}

대상자가 높낮이 조절이 가능한 테이블에 바로 엎드린 자세에서 어 깨관절 $90^{\circ}$ 벌림, 팔꿈치 관절 $90^{\circ}$ 굽힘을 유지하도록 하였다. 어깨뼈를 밑으로 내리면서 어깨관절이 바깥 돌림의 동작이 유발되도록 실시하 였다.

\section{3. 실험도구}

본 연구에 사용된 측정 도구로는 3 개의 등세모근과 앞톱니근의 근 활 성도를 비교하기 위해 16채널 무선 표면 근전도(Noraxon TeleMyo DTS wireles system, Noraxon Inc., AZ, USA)을 사용하였으며, 본 장비 의 8 채널을 이용하여 위등세모근, 중간등세모근, 아래등세모근, 앞톱 니근에 표면 전극(Electrode SEED T246H)을 부착하였다. 전극을 부 착하기 전에 대상자의 근육에 전극을 붙일 위치를 선정한 후 피부 저 항을 줄이기 위해 면도하고, 소독용 알코올 솜으로 피부 표면을 깨끗
이 닦았다. 실험 시 대상자들의 자세 설정과 고정을 위해 관절 각도계 (goniometer,JAMAR, USA)를 사용하였다.

\section{(1) 근전도 전극 부착 위치}

일관된 정확한 전극 부착을 위해 동일한 검사자가 모든 대상자에게 실시하였고, 자발적인 수축(voluntary contraction)을 확인하여 전극 부착 부위를 확인한 후에 전극을 부착하였다. 위등세모근, 아래등세 모근, 중간등세모근, 앞톱니근에 부착하였고, 위등세모근은 7번 목뼈 의 가로돌기와 어깨뼈 봉우리(acromion)의 가운데 부분, 아래등세모 근은 어깨뼈의 아래각(inferior angle)에서 $55^{\circ}$ 의 각도로 기울어지게 부착하였다. 중간등세모근은 3 번 등뼈와 어깨뼈의 안쪽모서리(medial border)의 가운데 부분, 앞톱니근은 어깨뼈 아래각(inferior angle)과 같은 겨드랑 아래에 부착하였다. ${ }^{21}$

\section{(2) 근전도 신호의 기록 및 처리}

근전도 신호의 표본 추출율(sampling rate)은 $1,000 \mathrm{~Hz}$ 로 하였고, 노치 필터(notch filter)는 $60 \mathrm{~Hz}$ 로, 밴드 패스 필터(band pass filter)는 10-500 $\mathrm{Hz}$ 로 설정하였다. 각 근육의 활동전위를 표준화시키기 위해 최대 수 의적 수축(maximal voluntary isometric contraction, MVIC)을 사용하 였다. 각 근육의 최대 수의적 수축값은 3 번 측정하여 평균값을 구하 였으며, 최대 수의적 수축 시 5 초간 자료 값을 구한 후, 처음과 끝부분 의 각 1 초를 제외한 3 초 동안의 평균 근전도 신호량을 $\%$ 최대 수의적 수축(\%MVIC)으로 사용하였다.

\section{4. 분석방법}

본 연구를 통하여 수집된 자료의 분석은 SPSS 18.0 for window를 이용 하여 각 변인들에 대한 평균 및 표준편차를 산출하여 비교 분석하였 다. 일원배치분산분석(One way ANOVA)을 사용하여 운동 방법에 따 른 등세모근(위등세모근, 중간등세모근, 아래등세모근)과 앞톱니근 의 근 활성도 차이를 분석하였고, 사후 검정은 샤페 검증(Sheffe test) 을 실시하였다. 통계학적 유의 수준( $(\alpha)$ 는 0.05 로 설정하였다.

\section{결 과}

\section{1. 연구대상자의 일반적 특성}

본 연구는 우세측 팔이 오른쪽인 건강한 성인으로 남자 17 명, 여자 15 명 총 32 명을 대상으로 실시하였다. 대상자의 평균 나이는 $26.83 \pm 1.77$ 세, 평균 신장은 $170.16 \pm 7.40 \mathrm{~cm}$, 평균 체중은 $64.52 \pm 9.3 \mathrm{~kg}$ 이었다(Table 1).

\section{2. 운동 방법에 따른 각 근육의 근 활성도 비교}

$\mathrm{PF}, \mathrm{PR}, \mathrm{MPC}$ 운동에서는 각 근육의 근활성도에서 유의한 차이가 있 
었고, 사후검정에서는 아래등세모근(lower trapezius, LT)과 중간등세 모근(middle trapezius, MT)의 근 활성도가 위등세모근(upper trapezius, UT)과 앞톱니근(serratus anterior, SA)의 근 활성도 보다 유의하게 크게 나타났다 $(\mathrm{p}<0.00)($ Table 2$)$.

$\mathrm{ERP}$ 운동에서도 각 근육의 근 활성도에서 유의한 차이가 있었으 며, 사후검정에서는 위등세모근(UT)의 근 활성도가 중간등세모근 (MT), 아래등세모근(LT), 앞톱니근(SA)의 근 활성도 보다 유의하게 크게 나타났다 $(\mathrm{p}<0.00)$ (Table 2).

\section{고 찰}

본 연구는 정상 성인 32 명을 대상으로 어깨 굽힘 또는 벌림 각도 $90^{\circ}$ 이하에서 아래등세모근의 근력 증진을 위해 가장 적합한 운동 방법 을 찾고자 하였다. 어깨뼈는 어깨의 움직임과 관절 안정성에 중요한 역할을 하며, 주로 등세모근과 앞톱니근의 활동에 의해 이루어진다. ${ }^{4}$ 따라서 근전도 측정 도구를 이용하여 4 가지 아래등세모근 운동 방법 (PF, PR, MPC, ERP) 시 운동에 따른 각 근육의 근 활성도를 측정 및 분석하였다. 연구 결과, 아래등세모근(LT), 중간등세모근(MT), 위등 세모근(UT), 앞톱니근(SA)의 근 활성도가 운동 방법에 따라 유의한 차이를 보였다.

$\mathrm{PF}$ 운동 시 $\mathrm{LT}(40.36 \pm 5.33 \% \mathrm{MVIC})$ 와 $\mathrm{MT}(40.98 \pm 8.06 \% \mathrm{MVIC})$ 의 근 활성도가 UT ( $32.69 \pm 11.51 \% \mathrm{MVIC})$ 와 SA $(3.17 \pm 2.7 \% \mathrm{MVIC})$ 의 근 활성도 보다 유의하게 크게 나타났다. Arlotta 드ㅇㅣㅡㄴ PF 운동 시 UT의 근 활성도가 LT의 근 활성도보다 상대적으로 높게 나타났다고 하였 는데 이는 단순히 지방 조직이나 근육 구조의 차이에 의한 것이거나 대상자가 건강하고 증상이 없음에도 불구하고 LT의 약화에 대한 보 상작용으로 이러한 현상이 나타났을 것이라고 보고하였다. 본 연구 의 결과에서 PF 운동 시 UT에 대한 LT의 비가 1.24 로 가장 낮았고,

Table 1. General characteristics of subjects

$(n=32)$

\begin{tabular}{lrc}
\hline & Mean \pm SD & \multicolumn{1}{c}{ Range } \\
\hline Age $(\mathrm{yr})$ & $26.83 \pm 1.77$ & $24.00-29.00$ \\
Height $(\mathrm{cm})$ & $170.16 \pm 7.40$ & $155.00-182.00$ \\
Weight $(\mathrm{kg})$ & $64.52 \pm 9.31$ & $49.00-81.00$ \\
\hline
\end{tabular}

MT의 근 활성도와 LT의 근 활성도에 유의한 차이가 나지 않은 것으 로 보아 PF는 LT를 우선적으로 강화하는 것이 목적 일 때 사용하기 에는 이상적이지 않을 것으로 생각된다.

PR 운동에서도 PF 운동과 동일하게 LT $(32.84 \pm 13.24 \% \mathrm{MVIC})$ 와 $\mathrm{MT}(40.59 \pm 15.28 \% \mathrm{MVIC})$ 의 근 활성도가 UT $(15.19 \pm 9.41 \% \mathrm{MVIC})$ 와 $\mathrm{SA}(5.54 \pm 3.19 \% \mathrm{MVIC})$ 의 근 활성도 보다 유의하게 컸다. 초기연구에 서 Moseley 등6은 PR 운동이 아래등세모근을 강화 시키는데 효과적 이라고 하였다. 최근 연구에서는 PR 운동이 MPC 운동과 비슷한 수 준의 LT활성도를 나타낸다고 보고되었다.11,22,23 $\mathrm{PR}$ 운동은 $\mathrm{MPC}$ 운동 과 비슷한수준으로 $\mathrm{LT}$ 를 선택적으로 수축시킬 수 있기 때문에 MPC 운동이나 PR운동을 이용하여 LT근육을 선택적으로 강화하는데 효 과적일 것이라고 하였다. 다른 $\mathrm{PR}$ 운동의 선행 연구에서 $\mathrm{PR}$ 운동은 LT의 가장 높은 양의 근 활성도를 나타내었으나 이 활성도량은 PF또 는 MPC 운동 시 생성된 근 활성도와 유의한 차이가 없었다고 보고하 였다." PR운동은 등세모근의 아래 섬유만 선택적인 수축을 나타내 지 않고 중간 섬유와 비슷한 근 활성도 결과를 보여주었다. 등세모근 의 중간섬유와 아래섬유 사이의 해부학 및 기능적 연결 때문에 서로 우선적 또는 선택적으로 활성화 시키는 것은 불가능 할 수 있을 것으 로 보인다.

$\mathrm{MPC}$ 운동에서는 LT의 근 활성도가 높게 나타났지만, 그 보다도 $\mathrm{MT}$ 의 근 활성도가 더 높게 나타났고 두 근육 사이에 유의한 차이는 없었다(p>0.05). Weon과 Yong ${ }^{24}$ 은 여러 가지 운동 방법 중에서 MPC 운동이 LT를 선택적으로 강화시킬 수 있는 가장 효과적인 운동이라 고 하였고 MPC 운동이 위등세모근/아래등세모근의 비가 유의하게 낮았다고 보고하였다. Kendall 등 ${ }^{18}$ 은 MT가 어깨뼈의 벌림과 안정화, $\mathrm{LT}$ 가 어깨뼈의 위쪽돌림과 내림, 안정화에 기여한다고 하였다. MPC 동작은 이러한 모든 움직임을 통합하므로 근 활성도가 MT와 LT에 서 비슷하게 나타나고, 선택적인 수축의 비율 또한 비슷하게 나타내 는 것으로 생각된다. 따라서 이러한 결과는 MPC 운동이 LT의 근 활 성도만 보고 평가하였을 때는 좋은 운동일 수 있으나, 선택적으로 강 화시키기 위한 운동으로는 부적절 할 것으로 예상된다.

$\mathrm{ERP}$ 운동에서는 $\mathrm{LT}(49.37 \pm 2.63 \% \mathrm{MVIC})$ 의 근 활성도가 $\mathrm{MT}(21.28$ $\pm 8.12 \% \mathrm{MVIC})$, UT $(17.83 \pm 9.43 \% \mathrm{MVIC}), \mathrm{SA}(15.06 \pm 6.08 \% \mathrm{MVIC})$ 의 근 활성도보다 유의하게 높았다. Ekstrom 등13은 ERP 운동 동안 LT의

Table 2. One-way ANOVA for shoulder muscle activities during four types of exercises

\begin{tabular}{lllllll}
\hline & \multicolumn{1}{c}{ LT } & \multicolumn{1}{c}{ MT } & UT & SA & F & P \\
\hline PF & $40.36 \pm 5.33$ & $40.98 \pm 8.06$ & $32.69 \pm 11.51$ & $3.17 \pm 2.70$ & 27.32 & $0.00^{*}$ \\
PR & $32.84 \pm 13.24$ & $40.59 \pm 15.28$ & $15.19 \pm 9.41$ & $5.54 \pm 3.19$ & 10.73 & $0.00^{*}$ \\
MPC & $32.89 \pm 7.49$ & $35.18 \pm 7.61$ & $17.04 \pm 13.17$ & $4.88 \pm 2.36$ & 14.44 & $0.00^{*}$ \\
ERP & $49.37 \pm 12.63$ & $21.28 \pm 8.12$ & $17.83 \pm 9.43$ & $15.06 \pm 6.08$ & 16.2 & $0.00^{*}$ \\
\hline
\end{tabular}

Value indicates mean \pm standard deviation, *statistically significant at the level of $\mathrm{p}<0.05$, LT: lower trapezius, MT: middle trapezius, UT: upper trapezius, SA: serratus anterior, PF: posterior fly, PR: prone row, MPC: modified prone cobra, ERP: external rotation in prone position. 
근 활성도를 $50 \pm 21 \% \mathrm{MVIC}$ 으로 보고하여 본 연구와 유사하게 나타 났다. 또한 Pontillo 등 25 은 조사된 4개의 운동 중 ERP 운동에서 UT의 근 활성도에 대한 LT의 근 활성도 비율이 2.35 라고 보고하였는데 본 연구에서도 이와 유사하게 UT에 대한 LT의 근 활성도가 2.77 로 4 개 의 운동 중에서 가장 높았다. 또 다른 선행 연구에서도 ERP 운동이 $\mathrm{UT}$ 의 활성화를 줄이고 LT의 활성화를 촉진시키면서 $\mathrm{SA}$ 운동을 하는 데 적합하다고 말하였다. ${ }^{26-28}$ 본 연구에서 $\mathrm{SA}$ 의 근 활성도가 $\mathrm{PR}$ 과 $\mathrm{MPC}$ 운동보다 PF와 ERP 운동에서 유의하게 컸다. PF운동과 ERP운 동에서 SA의 활성도에 유의한 차이는 보이지 않았으나 $\mathrm{PF}$ 운동은 $\mathrm{MT}$ 와 UT를 동시에 많이 쓰이면서 SA는 상대적으로 낮았고, 그에 비해 $\mathrm{ERP}$ 운동은 LT와SA가 많은 활성도를 보이고 MT와 UT는 낮았다. 따 라서 ERP는 LT와 SA 근육을 효과적으로 수축 시킬 수 있을 것으로 생각된다.

본 연구에서는 4 가지의 어깨 운동 방법 중 ERP 운동이 아래등세모 근을 자극하는데 가장 효과적인 운동이라는 결과를 보였다. 또한 $\mathrm{ERP}$ 운동은 4 가지 운동 중 아래등세모근의 근 활성도와 위등세모근 (UT) 및 아래등세모근(LT)에서 가장 높게 나타났으며, 앞톱니근(SA) 의 활성화에도 제일 효과적인 것으로 보였다. 결론적으로 ERP 운동 은 어깨 굽힘이나 벌림 $90^{\circ}$ 이하에서 운동 수행이 필요한 환자들에게 아래등세모근을 선택적으로 강화시킬 수 있는 최적의 운동 방법이 라 생각되며, 부가적으로 어깨 초기 재활에 필수적인 어깨 돌림근(rotator muscle)도 함께 강화시킬 수 있어 어깨의 기능적 훈련에 효과적 으로 기여할 수 있으며 향후 어깨 초기 재활 훈련에 유용한 자료로 제공 될 것으로 기대 된다. 그러나 운동 중에 목표 근육 위로 전극과 피부의 움직임이 허용되었고 특정 근육 위에 전극을 배치하고 운동 중 전극이 최대한 움직이지 않고 측정될 수 있도록 노력하였지만 전 극의 위치가 미세하게 이동되었다는 한계가 있다. 또한 본 연구에서 모집한 대상자는 대체적으로 젊고 활동적인 정상 성인이었기 때문에 결과는 활동적이지 않거나 비만, 신체적인 병리를 포함한 대상자 집 단을 고려한다면 완전히 일반화 될 수 없는 한계가 있다. 따라서 향후 연구에서는 이러한 제한점을 고려한 연구가 실시되어야 할 것으로 기대한다.

\section{REFERENCES}

1. Hess SA. Functional stability of the glenohumeral joint. Man Ther. 2005;5(2):63-71

2. Kronberg M, Nemeth G, Brostrom LA, Muscle activity and coordination in the normal shoulder. an electromyographic study. Clin Orthop Relat Res. 1990(257):76-85.

3. Ludewig PM, Braman JP. Shoulder impingement: biomechanical considerations in rehabilitation. Man Ther. 2011; 16(1):33-9.

4. Ludewig PM, Cook TM. Alterations in shoulder kinematics and associ- ated muscle activity in people with symptoms of shoulder impingement. Phys Ther. 2000;80(3):276-91.

5. Neumann DA. Kinesiology of the musculoskeletal system. 1st ed. St Louis, Mosby, 2002:118-32.

6. Moseley JB Jr, Jobe FW, Pink M et al. Emg analysis of the scapular muscles during a shoulder rehabilitation program. Am J Sports Med. 1992;20(2):128-34.

7. Cools AM, Declercq GA, Cambier DC et al. Trapezius activity and intramuscular balance during isokinetic exercise in overhead athletes with impingement symptoms. Scand J Med Sci Sports. 2007;17(1):25-33.

8. Cools AM, Witvrouw EE, Declercq GA et al. Evaluation of isokinetic force production and associated muscle activity in the scapular rotators during a protraction-retraction movement in overhead athletes with impingement symptoms. Br J Sports Med. 2004;38(1):64-8.

9. Lin H, Chie W, Lien H. Epidemiological analysis of factors influencing an episode of exertional rhabdomyolysis in high school students. Am J Sports Med. 2006;34(3):481-6.

10. Mottram SL. Dynamic stability of the scapula. Man Ther. 1997;2(3):12331.

11. Arlotta M, LoVasco G, McLean L. Selective recruitment of the lower fibers of the trapezius muscle. J Electromyogr Kinesiol. 2011;21(3):403410.

12. De Mey K, Danneels LA, Cagnie B et al. Conscious correction of scapular orientation in overhead athletes performing selected shoulder rehabilitation exercises: the effect on trapezius muscle activation measured by surface electromyography. J Orthop Sports Phys Ther. 2013;43(1):310 .

13. Ekstrom RA, Donatelli RA, Soderberg GL. Surface electromyographic analysis of exercises for the trapezius and serratus anterior muscles. J Orthop Sports Phys Ther. 2003;33(5):247-58.

14. Ha SM, Kwon OY, Cynn HS et al. Comparison of electromyographic activity of the lower trapezius and serratus anterior muscle in different arm-lifting scapular posterior tilt exercises. Phys Ther Sport. 2012;13(4): 227-32.

15. Smith J, Dahm DL, Kaufman KR et al. Electromyographic activity in the immobilized shoulder girdle musculature during scapulothoracic exercises. Arch Phys Med Rehabil. 2006;87(7):923-7.

16. Witt D, Talbott N, Kotowski S. Electromyographic activity of scapular muscles during diagonal patterns using elastic resistance and free weight. Int J Sports Phys Ther. 2011;6(4):322-32.

17. Shannon $\mathrm{m}$. Lower trapezius muscle strength in individuals with unilateral neck pain. N Am J Sports Phys Ther. 2011;41(4):260-5

18. McCann PD, Wootten ME, Kadaba MP et al. A kinematic and electromyographic study of shoulder rehabilitation exercises. Clin Orthop Relat Res. 1993(288):179-188.

19. Kendall FP, McCreary EK, Provance PG et al. Muscles: testing and function, with posture and pain. 5th ed. Baltimore, Lippincott Williams and Wilkins, 2005:17-330.

20. Lear LJ. Gross MT. An electromyographical analysis of the scapular stabilizing synergists during a push-up progression. J Orthop Sports Phys Ther. 1998;28(3):146-57.

21. Criswell E. Cram's introduction to surface electromyography. 2nd ed. Sudbury, Jones and Bartlett Publishers, 2011.

22. Kim KY, Kim SY. The effect of lower trapezius strengthening exercises 
on pain, disability, cervical range of motion and strength of lower trapezius in patients with unilateral neck pain: a controlled randomized trial. Physical Therapy Korea. 2015;22(1):58-68.

23. Kim BG, Lee MH. A comparison of EMG activity for the middle and lower trapezius muscle in the frontal and scapular plane according to shoulder abduction angles. PNF \& Mov. 2016;14(2);131-7

24. Weon JH, Yong JH. Comparison of the EMG activities of scapular upward rotators and other scapular muscles among three lower trapezius strengthening exercises. Physical Therapy Korea, 2013;20(3):27-35.

25. Pontillo M, Orishimo KF, Kremenic IJ et al. Shoulder musculature activity and stabilization during upper extremity weight-bearing activities. N
Am J Sports Phys Ther. 2007;2(2):90-6

26. Escamilla RF, Yamashiro K, Paulos L et al. Shoulder muscle activity and function in common shoulder rehabilitation exercise. Sports Med. 2009;39(8):663-685.

27. Decker MJ, Hintermeister RA, Faber KJ et al. Serratus anterior muscle activity during selected rehabilitation exercises. Am J Sports Med. 1999;27(6):784-91.

28. Hardwick DH, Beebe JA, McDonnell MK et al. A comparison of serratus anterior muscle activation during a wall slide exercise and other traditional exercises. J Orthop Sports Phys Ther. 2006;36(12):903-10. 